\title{
Differential apoptosis gene expressions of rhabdomyosarcoma cells in response to enterovirus 71 infection
}

Weifeng Shi ${ }^{{ }^{* \dagger}}$, Xiang $\mathrm{Li}^{1+}$, Xueling Hou ${ }^{1}$, Hongjun Peng ${ }^{1}$, Qingbo Jiang ${ }^{1}$, Mei Shi ${ }^{1 \dagger}$, Yun $\mathrm{Ji}^{1}$, Xiping Liu ${ }^{1}$ and Jinbo Liu ${ }^{2}$

\begin{abstract}
Background: Enterovirus 71 (EV71) infection can induce the apoptosis of infected cells. The aim of this study is to explore the effect of EV71 infection on apoptosis mechanisms in virus-infected human rhabdomyosarcoma (RD) cells.

Methods: The apoptosis of RD cells was examined using annexin V-FITC/PI by flow cytometry and cytokines were detected by ELISA. Cellular RNA was extracted and transcribed to CDNA. PCR array was employed to analyze the expressions of 84 apoptotic genes from EV71-infected RD cells at 8 and $20 \mathrm{~h}$ postinfection, respectively. In addition, the expressions of FasL, caspase, AKT2, JNK1/2, C-Jun and NF-KB proteins were detected by western blotting.

Results: Flow cytometry demonstrated that the apoptosis or death of EV71-infected RD cells was increased by $37.1 \%$ with a multiplicity of infection (MOI) of 5 at $20 \mathrm{~h}$ postinfection. The production of IL-4, IL-10 and TNF-a was enhanced by the subsequent EV71 infection. PCR array revealed significant changes in the expressions of apoptotic genes. Among 84 genes, 42 genes were down-regulated after EV71 infection at $8 \mathrm{~h}$, whereas 32 genes were up-regulated at $20 \mathrm{~h}$ postinfection. Moreover, the ligands of TNF superfamily such as FasL, CD40L and TNF-a were significantly up-regulated and enhanced the expressions of apoptosis-related cysteine peptidases, including caspase-10, -8, -7 and -3. In addition, EV71 infection induces the phosphorylation of AKT2, JNK1/2, c-Jun and NF-KB at $20 \mathrm{~h}$ postinfection.

Conclusion: PCR array for the determination of apoptosis gene expressions is an informative assay in elucidating biological pathways. During the early stage of EV71 infection, the apoptotic process of RD cells is significantly delayed. EV71 infection can also induce the expressions of FasL, TNF-a and CD40L, which contribute to the apoptosis of RD cells.
\end{abstract}

Keywords: Enterovirus 71, PCR array, FasL, CD40L, Apoptosis

\section{Background}

EV71 is a member of Picornaviridae family composed of a large number of small non-enveloped, positive strand RNA viruses with a genome size of approximately $7.4 \mathrm{~kb}$ [1,2]. Both EV71 and coxsackievirus A16 (CVA16) belong to the human enterovirus A species, which are major causative agents causing hand, foot, and mouth

\footnotetext{
*Correspondence: shiweifeng67@163.com

†Equal contributors

'Department of Clinical Laboratory, The Third Affiliated Hospital of Suzhou University, Changzhou, Jiangsu 213003, China

Full list of author information is available at the end of the article
}

disease (HFMD) in children [3]. However, patients infected with EV71 are liable to cause aseptic meningitis, encephalomyelitis, pulmonary edema and death $[4,5]$. EV71 was first identified in 1969 in California when it was isolated from the feces of an infant suffering from encephalitis [6]. Subsequently, EV71 infection is widely popular in many countries and regions, such as Taiwan, Singapore, Malaysia, and Hongkong, as well as mainland China [7-11]. Up to now, the molecular pathogenesis of EV71 infection is still elusive.

Apoptosis is essential for the maintenance of homeostasis in the immune system, which is characterized

\section{Biomed Central}


morphologically by internucleosomal DNA cleavage, chromatin condensation, membrane blebbing, cell shrinkage, apoptotic body formation and cell death. The process may be triggered by interactions of pro-apoptotic stimuli coupled with various factors such as death receptors, mitochondrial apoptotic pathway and endoplasmic reticulum stress $[12,13]$. In an attempt to prevent viral replication, dissemination or persistent infection of cells, many protective measures are actually involved in the induction of apoptosis that is the host response to curtail the reproductive cycle of the virus through premature lysis $[14,15]$. In addition, the apoptosis of host cells can facilitate macrophages to phagocytose dead cells for preventing dysregulated inflammatory reactions or initiating specific immune responses in the infected host [16].

In order to elucidate the molecular basis of the host response to viral infection, anti-apoptotic response is essential for identifying the targets to reduce cell or tissue damage resulting from inflammatory responses. As described previously, EV71 can induce the apoptosis of human endothelial cells, T lymphocytes and nerve cells [17-19]. However, little information is known about the mechanisms of RD cell apoptosis by EV71 infection. In this study, PCR array was used to detect 84 genes associated with apoptosis and explore the host response at different time points after EV71-infection in RD cells as well as molecular mechanisms of apoptosis.

\section{Methods}

\section{Antibodies and chemicals}

Dulbecco's modified Eagle's medium (DMEM) and fetal bovine serum (FBS) were purchased from Thermo Scientific HyClone (UT, USA). Anti-caspase-8, -3, AKT2, JNK1/2, с-Jun and NF-кB p65 rabbit polyclonal antibodies were purchased from Signalway Antibody (Pearland, TX, USA). Rabbit polyclonal phospho-specific antibodies, including p-JNK1/2, p-AKT2, c-Jun and p-NF-kB p65 antibodies were also from Signalway Antibody. Anti-caspase-10, -7, and FasL were from Cell Signaling Technology (Beverly, MA, USA). Goat antiglyceraldehyde-3-phosphate dehydrogenase (GAPDH), $\beta$-actin antibodies and IgG secondary horseradish peroxidase (HRP) conjugated were from Signalway Antibody.

\section{RD cell culture and EV71 infection}

RD cells were purchased from CBTCCCAS (Chinese Academy of Sciences Cell Bank of Type Culture Collection) and cultured in high glucose DMEM supplemented with $10 \% \mathrm{FBS}$ at $37^{\circ} \mathrm{C}$ in a humidified incubator with $5 \% \mathrm{CO}_{2}$. When cells reached up to $90 \%$ confluence, the medium was removed and the monolayer cells were washed once with PBS. One batch of uninfected RD cells in $25 \mathrm{~cm}^{2}$ culture flask were used as the control, while another two batches of RD cells were infected with
UV-inactivated EV71 strain CCTCC/GDV083 (ATCC VR-784) (China Center for Type Culture Collection, CCTCC) and alive EV71 strain GDV083 at an MOI of 5 in a $4 \mathrm{~mL}$ of virus inoculum diluted with maintenance medium. Approximately $1 \times 10^{6}$ cells were incubated with EV71 at an MOI of 5 or as indicated and allowed to absorb for $2 \mathrm{~h}$ at $37^{\circ} \mathrm{C}$. Unbounded viruses were removed by washing the cells with medium, and $15 \mathrm{~mL}$ of maintenance medium was added. Infected cells and culture supernatants were collected at different time intervals. Virus titers in both supernatant (extracellular) and cell lysate (intracellular) were determined using plaque assays, as described previously, at the designated time points [20].

\section{Viability of RD cells}

The viability of RD cells was assayed using the trypan blue exclusion method. Cells were cultured with EV71 at an MOI of 5. After different incubation periods, cells were re-suspended in trypan blue solution and counted under a light microscope. RD cells without being stained by trypan blue were counted as the viable cells. The viability of RD cells was calculated through the total number of cells dividing by the number of viable cells.

\section{Evaluation of apoptosis in RD cells by annexin V-FITC/PI binding assay}

RD cells were seeded at a density of $1 \times 10^{5}$ cells onto pre-treated coverslips in a 6-well plate. After incubation at $37^{\circ} \mathrm{C}$ overnight, the cells were inoculated at an MOI of 5 with EV71 strain and UV-inactivated EV71 strain for $2 \mathrm{~h}$. After absorption, the inoculum was removed, and replaced with $3 \mathrm{~mL}$ of maintenance medium. The cells were subjected to incubation for another $20 \mathrm{~h}$, and then fixed with $3.7 \%$ paraformaldehyde for $30 \mathrm{~min}$ at room temperature. The coverslips were stained by annexin $\mathrm{V}$ - fluorescein isothiocyanate (FITC) / propidium iodide (PI) (Vector Laboratories, Burlingame, CA, USA) and observed under a fluorescence microscope. Flow cytometry was performed with Vybrant apoptosis assay kit (Molecular Probes, Eugene, OR) according to the manufacturer's instructions. A total of $2 \times 10^{4} \mathrm{RD}$ cells were infected with EV71 and harvested at 8 and $20 \mathrm{~h}$ postinfection. Following washes in cold phosphatebuffered saline (PBS) and re-suspension in $195 \mu \mathrm{L}$ of $1 \times$ annexin-binding buffer, $5 \mu \mathrm{L}$ annexin $\mathrm{V}$ - FITC and $10 \mu \mathrm{L}$ PI were added to the cells and incubated at room temperature for $15 \mathrm{~min}$. Stained cells were then analyzed by flow cytometry using FACS Canto System (BD Biosciences, San Jose, CA). Normal living cells were not stained with annexin V-FITC and PI, while cells stained with annexin V-FITC alone were defined as the early stage of apoptosis and the cells stained with both annexin V-FITC and PI were defined as the late stage 
of apoptosis or necrosis. Quantitative analysis was conducted by determining the percentage of stained cells among total cells.

\section{ELISA for cytokines}

RD cells were infected with EV71 at an MOI of 5 for $2 \mathrm{~h}$ at $37^{\circ} \mathrm{C}$. Infected RD cells were washed 2 times and cultured in DMEM medium. Culture supernatants were harvested at 0, 8, 20 and $32 \mathrm{~h}$ after EV71 infection. The expression levels of IL-4, IL-10 and TNF- $\alpha$ were measured by ELISA kits (R\&D System, USA) according to the manufacturer's protocols. All experiments were repeated three times.

\section{Total RNA preparation and PCR array}

After incubation at $37^{\circ} \mathrm{C}$ for 8 and $20 \mathrm{~h}$, both uninfected and infected RD cells were harvested for the extraction of total RNA. Total RNA was extracted by SV total RNA isolation system (Promega, Madison, WI, USA). A total of $1 \mathrm{mg}$ RNA for each sample was used for reverse transcription through RT-PCR Kit (catalog\#CTB101; CT biosciences, China) on the ABI 9700 thermocycler (ABI, Foster City, CA). PCR arrays were performed with customized PCR containing pre-dispensed primers (CT biosciences, China) on the LightCycler 480 (Roche Diagnostics, Mannheim, Germany) using SYBR MasterMix ((catalog\#CTB101; CT biosciences, China). Each PCR contained $10 \mathrm{ng}$ of synthesized cDNA. The thermocycler parameters were performed with an initial denaturation at $95^{\circ} \mathrm{C}$ for $5 \mathrm{~min}$ followed by 40 cycles of denaturation at $95^{\circ} \mathrm{C}$ for $15 \mathrm{~s}$, annealing at $60^{\circ} \mathrm{C}$ for $15 \mathrm{~s}$ and extension at $72^{\circ} \mathrm{C}$ for $20 \mathrm{~s}$. Relative changes in gene expressions were calculated using $\triangle \Delta \mathrm{Ct}$ (threshold cycle) method. The housekeeping genes such as B2M, ACTB, GAPDH, RPL27, HPRT1 and OAZ1 were used to normalize to the amount of RNA. Fold change values were calculated using the formula of 2- $\Delta \Delta \mathrm{Ct}$.

\section{Cell extract preparation and western blot analysis}

EV71-infected cells $(\mathrm{MOI}=5)$ were harvested as indicated. The pellet was washed and lysed with a lysis buffer (2\% sodium dodecyl sulfate, $35 \mathrm{mM} \beta$-mercaptoethanol, $50 \mathrm{mM}$ Tris- $\mathrm{HCl}$ [pH 6.8], $1 \mathrm{mM}$ phenylmethylsulfonylfluoride). Cell lysates were obtained by centrifugation at $13000 \mathrm{rpm}$ and $4^{\circ} \mathrm{C}$. Total protein concentrations were determined by the bicinchoninic acid protein assay kit (Pierce). Then, proteins were resolved by sodium dodecyl sulfate polyacrylamide gel electrophoresis (SDS-PAGE), and transferred to PVDF membranes (Millipore). Membranes were blocked for $2 \mathrm{~h}$ with $5 \%$ nonfat dry milk solution in Tris-buffered saline containing $0.1 \%$ Tween20, which were blotted with specific primary antibodies, followed by incubation with secondary antibodies conjugated with HRP. Blots were developed with an enhanced ChemiDoc ${ }^{\mathrm{TM}} \mathrm{XRS}^{+}$system (Biorad, USA).

\section{Statistical analysis}

All data were presented as the mean \pm SE. Statistical analyses were performed using GraphPad Prism software (San Diego, CA). P value less than 0.05 was considered as statistical significance.

\section{Results}

EV71 infection induced cytopathic effect in RD cells

Two batches of RD cells with three experimental models in each group were analyzed at 4, 8, 20, 32 and $48 \mathrm{~h}$ postinfection. Three models included uninfected control, mock-infection control with UV-inactivated EV71 strain GDV083 and EV71 strain GDV083 infection. The cell growth did not exhibit an obvious difference at 4 and $8 \mathrm{~h}$ postinfection. However, the viable cells revealed distinct decrease in EV71-infected model at 20, 32 and $48 \mathrm{~h}$ (Figure 1). Visible CPE was also observed in the infected cell culture (Figure 2). Viable cell counts for the uninfected and mock-infected controls were comparable without any potential "spillover" effects from the inoculum itself. In virus-infected cells, an obvious CPE was observed at $20 \mathrm{~h}$ postinfection. However, there was no significant change between mock control and uninfected control.

\section{Annexin V-FITC/PI fluorescent analysis of EV71-infected RD cells}

In normal cells, the phosphatidylserine (PS) was localized mainly on the membrane surface of cytoplasmic cells. However, PS could be translocated to the outer leaflet of the membrane during apoptosis. Dying cells stained with annexin $\mathrm{V}$ allowed for the detection of PS exposure as an early indicator of apoptosis. RD cells were infected by

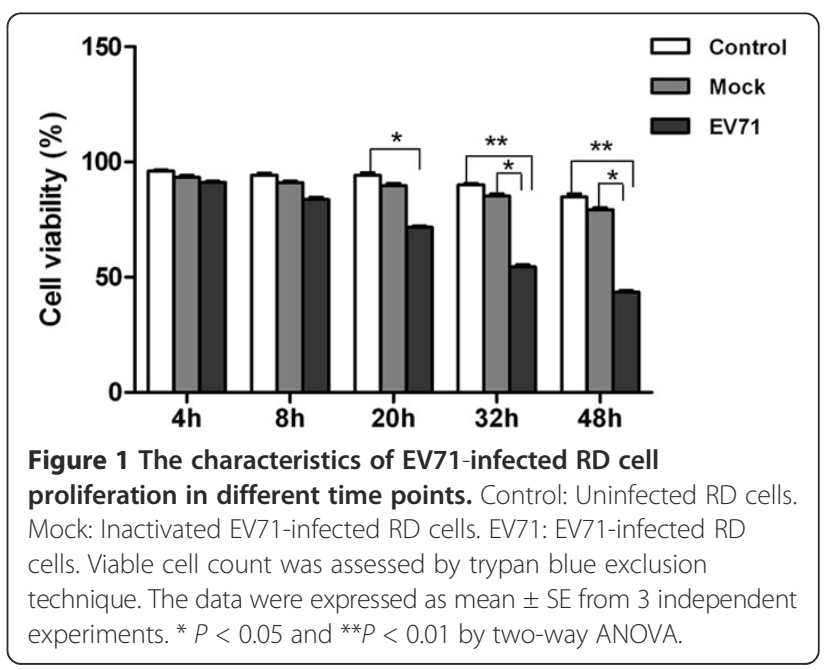



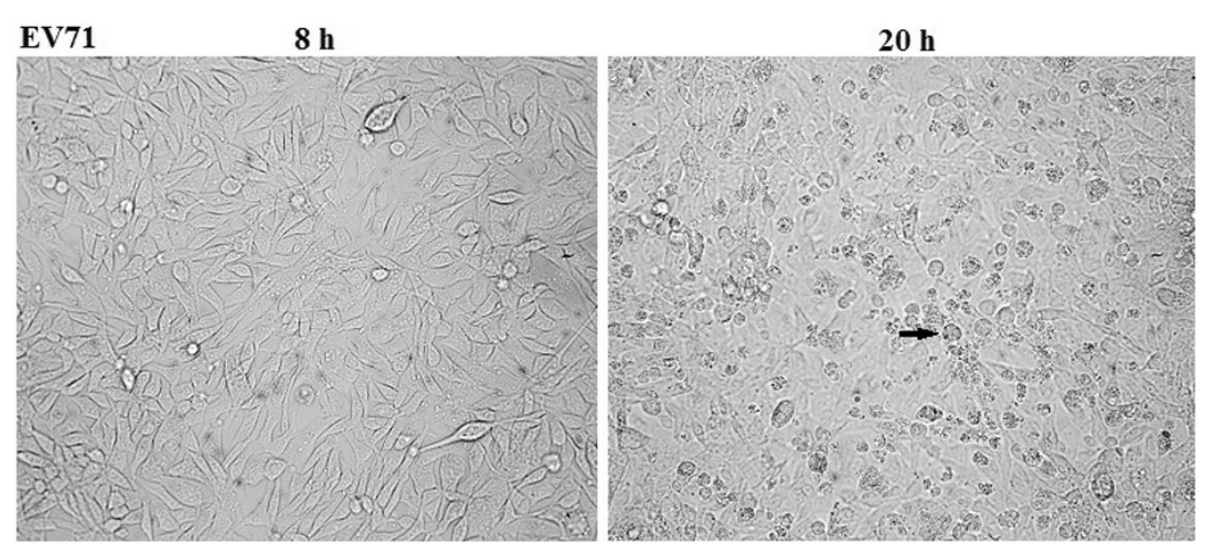

Figure 2 The morphology of EV71-infected RD cells. Following the infection at 8 and $20 \mathrm{~h}$ in RD cells, cell morphology was examined under a light microscope $(100 \times)$, and visible cell apoptosis was labeled by black arrow.

EV71 on glass coverslips at $20 \mathrm{~h}$, which stained with annexin V-FITC/PI and visualized under a fluorescence microscope. RD cell apoptosis or death was observed at 20 and $32 \mathrm{~h}$ postinfection (Figure 3 ). Meanwhile, RD cells were infected with EV71 and membrane change was measured using flow cytometry. As shown in Figure 4, $6.9 \%$ of RD cells showed membrane change at $8 \mathrm{~h}$, and $18 \%$ at $20 \mathrm{~h}$. Moreover, cell death or late apoptosis was $10.6 \%$ and $19.1 \%$ at 8 and $20 \mathrm{~h}$ postinfection, respectively.

\section{Cytokine levels of IL-4, IL-10 and TNF- $a$}

After EV71 infection at 0, 8, 20 and $32 \mathrm{~h}$, the culture supernatants of RD cells were harvested, and then the levels of cytokines such as IL-4, IL-10 and TNF- $\alpha$ were detected by ELISA. The results suggested that EV71 infection could trigger RD cells to release IL-4, IL-10 and TNF- $\alpha$ (Figure 5).

\section{PCR array of 84 apoptotic genes in RD cells during EV71 infection}

Cellular RNA was extracted and transcribed to cDNA in a $20 \mu \mathrm{L}$ reaction mixture for $25 \mathrm{~min}$ at $40^{\circ} \mathrm{C}$ using random primers and SuperScript II reverse transcriptase (Invitrogen) according to the manufacturer's instructions. The expression profile of 84 genes was generated. PCR amplification and melting curves were as shown in Figure 6. At $20 \mathrm{~h}$ postinfection, only 2 genes (c-Fos and IFN- $\beta 1$ ) exhibited 2.34 and 5.22-fold increases, while 42 genes revealed a significant down-regulation. After EV71 infection at $20 \mathrm{~h}$, the expression levels of 32 genes were larger than two fold based on PCR array. Particularly,

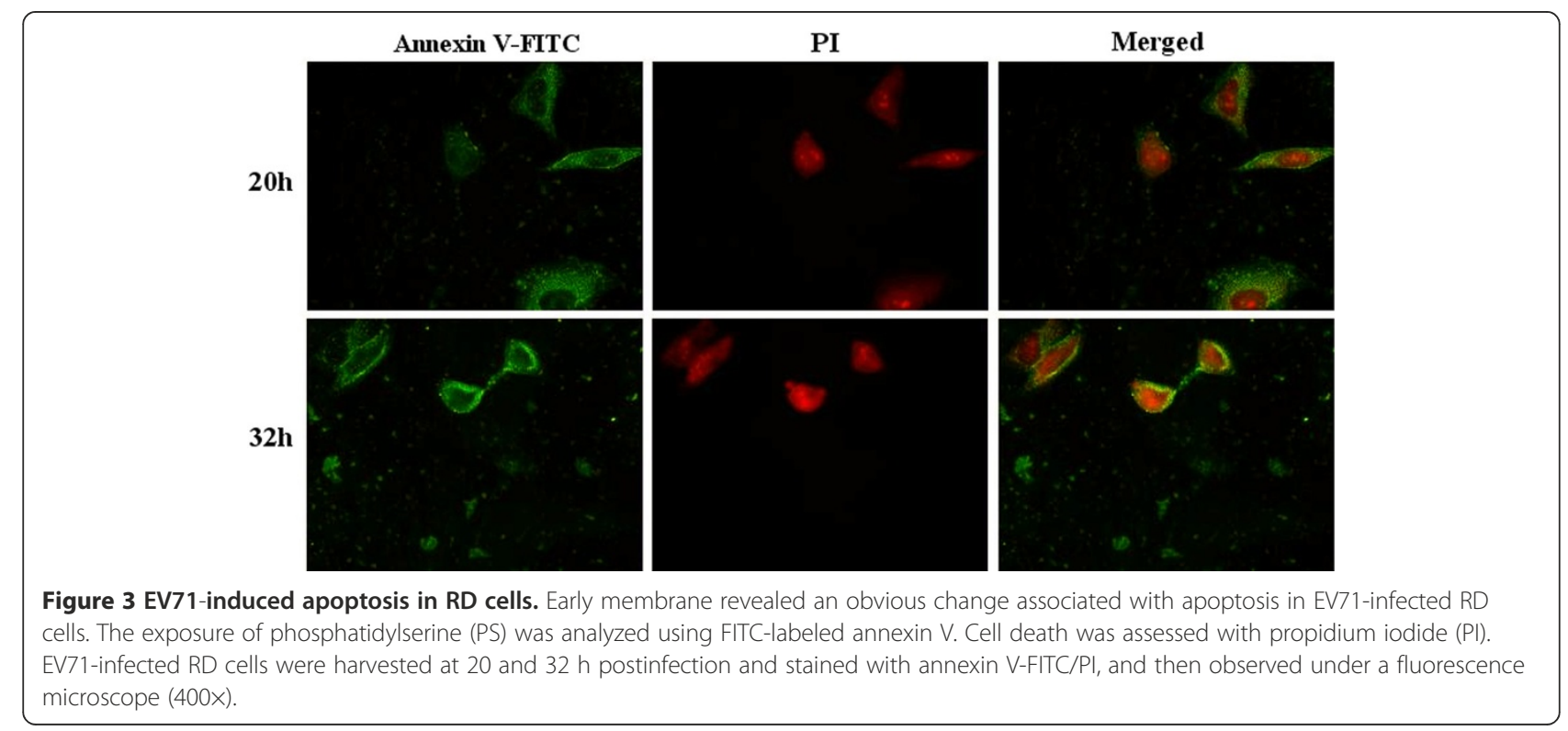




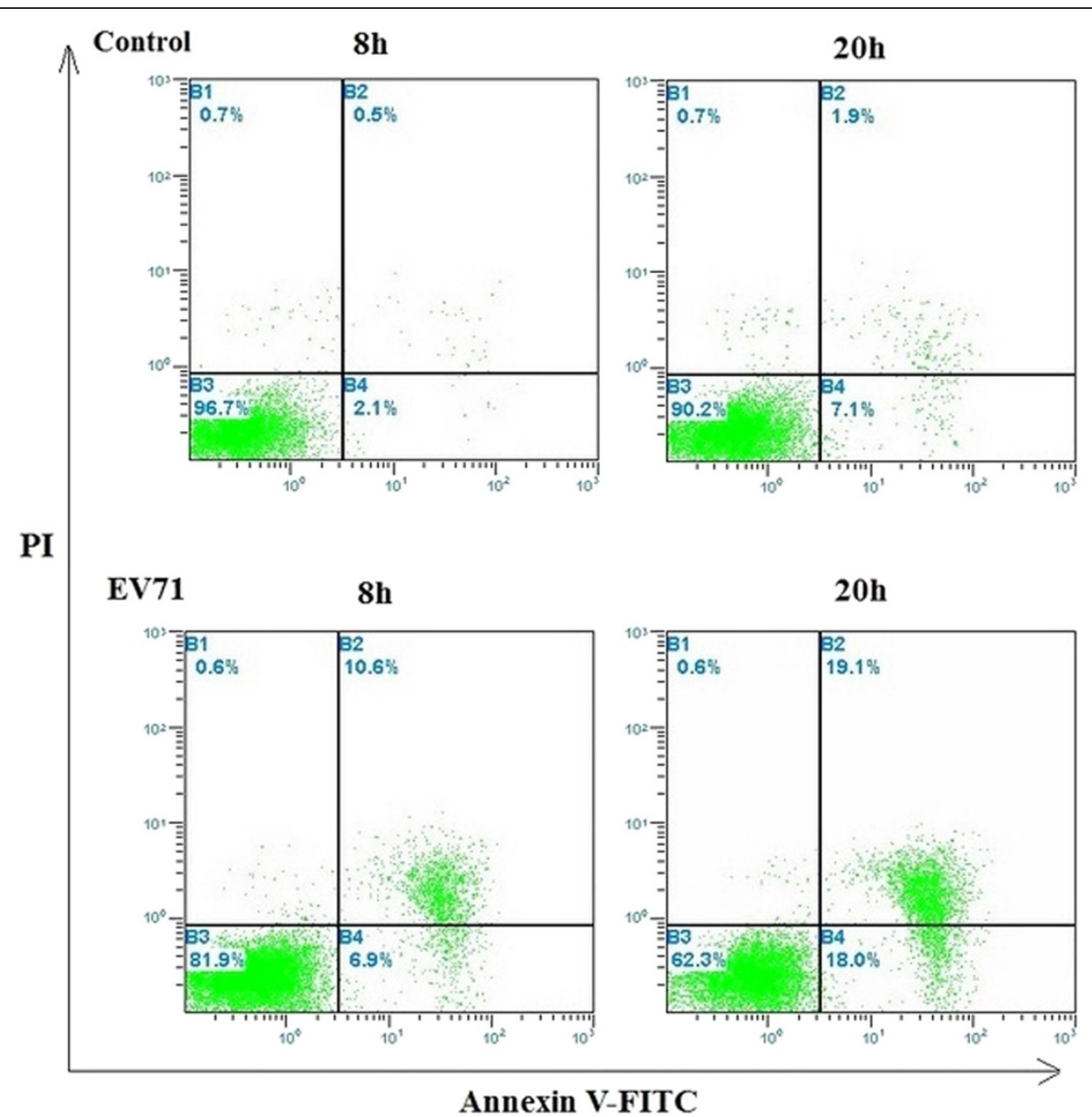

Figure 4 Membrane changes associated with apoptosis in EV71-infected RD cells. Control: Uninfected RD cells. EV71: EV71-infected RD cells. The exposure of phosphatidylserine (PS) was analyzed using FITC-labeled annexin V. Cell death was assessed using PI in a time course mode. EV71-infected RD cells were harvested at 8 and $20 \mathrm{~h}$ postinfection and cell death was evaluated by flow cytometry.

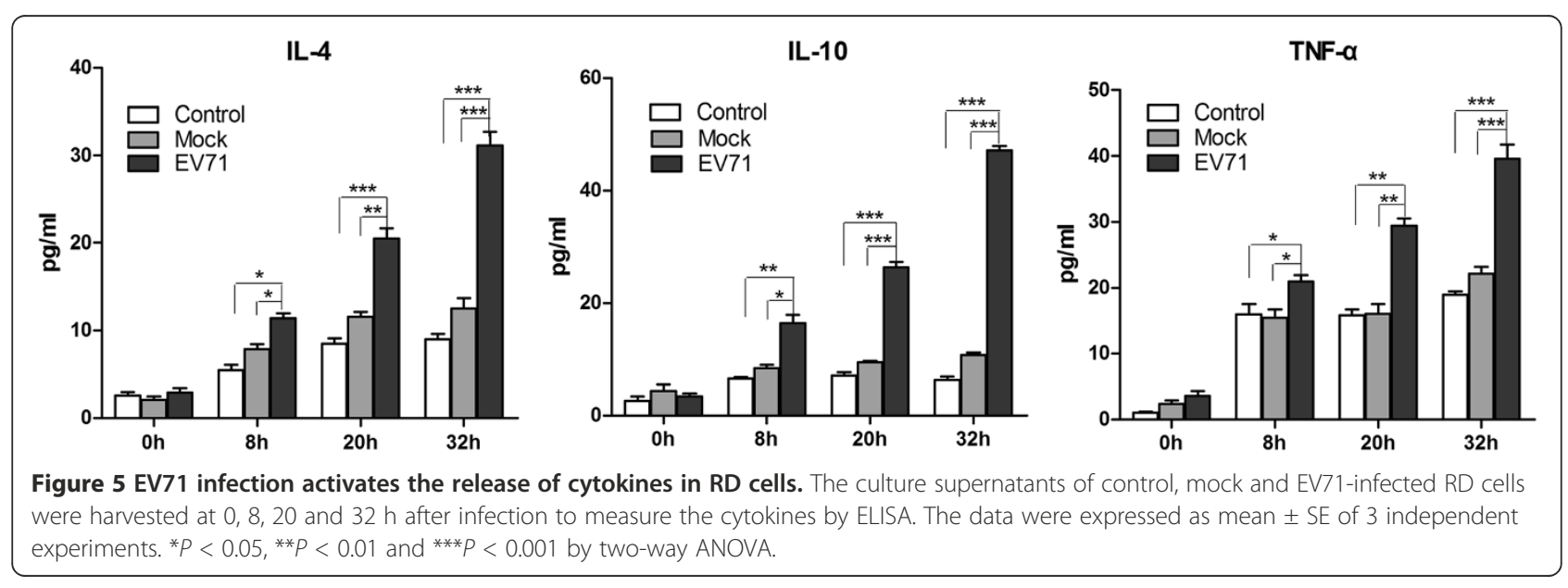



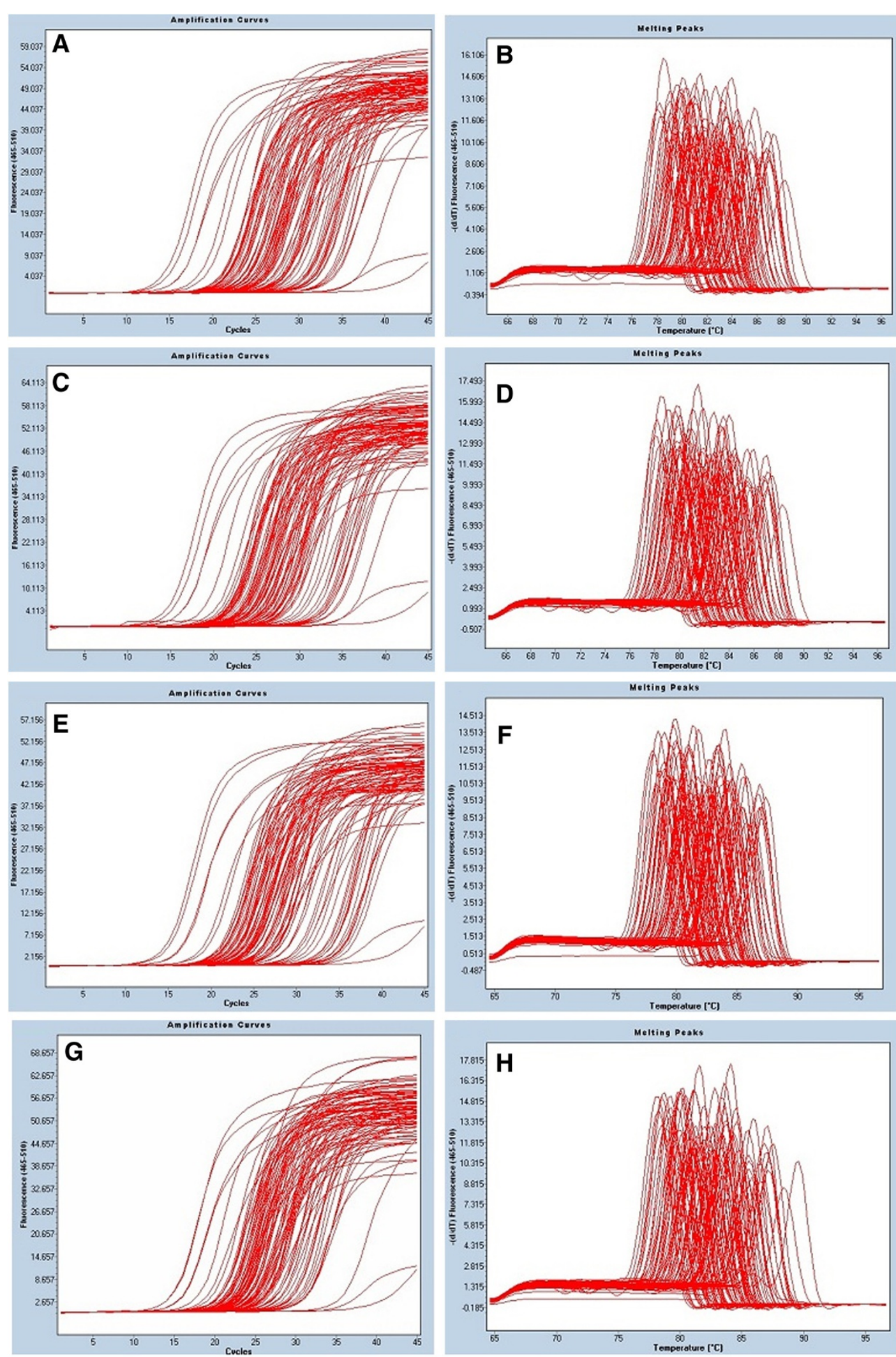

Figure 6 PCR amplification and melting curves. Uninfected Control: A, B and E, F; amplification curves and melting curves at 8 and 20 h, respecively. EV71-infected RD cells: $\mathbf{C}, \mathbf{D}$ and $\mathbf{G}, \mathbf{H}$; amplification curves and melting curves at 8 and 20 h postinfection by EV71, respecively. 
the ligands of the TNF superfamily including FasL, CD40L and TNF- $\alpha$ were significantly up-regulated (Table 1 ).

EV71 induced activation of death receptor signal pathway When RD cells were infected with EV71 at $20 \mathrm{~h}$, the expressions of caspase -10, -8, -7, -3 and FasL were highly elevated. Upon death ligand-receptor binding, caspase-10 is coupled to the multimeric Fas/TNF receptor complex via DED/FADD adaptor interaction. This complex may process procaspase- 10 and -8 into a large active subunit and a small subunit. Then cleaved caspase- 10 and -8 can further process other caspase members, including caspase- 7 and -3 , to initiate a caspase cascade, leading to programmed cell death. Interestingly, the gene expressions of CD40L, MEK4, MEK7 and c-Fos were induced by $5.44,2.54,3.05$ and 3.23 fold in RD cells at $20 \mathrm{~h}$ posinfection. In addition, JNK1/2, NF-kB p65 and c-Jun were significantly activated and phosphorylated (Figure 7). Based on these results, putative pathways of apoptosis were predicted for EV71-infected RD cells (Figure 8).

\section{Discussion}

Apoptosis is characterized by DNA fragmentation, chromatin condensation, membrane blebbing, cell shrinkage and cell death. An increasing number of viruses can induce apoptosis at the late stage of infection. This process may be important for the spread of progeny viruses to the neighbor cells and for the protection of progeny viruses against host enzymes and antibodies. There are three major apoptotic pathways including death receptor (extrinsic), mitochondrial (intrinsic) and endoplasmic reticulum pathways, respectively. All of these pathways are observed in the cytoplasm $[21,22]$. The mechanisms of host defense can limit virus replication, enable infected cells apoptosis, release and exclude immature virus particles through lysosome or proteases. However, the viruses survive through a variety of ways which can interfere with the apoptosis of infected cells to evade or delay the early onset of apoptosis [16,23].

In order to confirm the pathophysiology of EV71 infection and host cellular responses, especially for apoptotic responses, we have employed PCR to analyze the expression changes of cellular genes during the infection process. The expression profiles of 84 pro- and antiapoptotic genes revealed a significant difference in various time points. With the onset of EV71 replication, the genes such as ACIN1, Akt, APAF1, caspase, CIDEB, DAPK, NF-kB1, STAT1 and p53 associated with apoptosis were interrupted at $8 \mathrm{~h}$ postinfection by apoptosissuppressing effect of EV71. Although many RNA viruses do not encode anti-apoptotic genes, the apoptosissuppressing mechanisms are still unclear. EV71 infection at $20 \mathrm{~h}$ postinfection could stimulate the up-regulation of genes such as FasL, CD40L, TNF- $\alpha$, TNFRSF10A
(DR4), Fas, caspase-10, -8, -7, -3 and XIAP involved in TNFR1 pathway in RD cells. FasL is a type II membrane protein in the TNF- $\alpha$ receptor family and Fas receptor binding with FasL can induce cell apoptosis [18,24]. Interestingly, the expressions of Fas, FasL and DR4 revealed an enhancement by 3.26, 7.53 and 2.03 fold in $\mathrm{RD}$ cells at $20 \mathrm{~h}$ postinfection, suggesting that the proteins involved in Fas receptor-mediated pathway were activated in EV71-infected RD cells. Furthermore, downstream proteins in the Fas pathway such as caspase-10, $-8,-7,-3$ and CIDEB were also significantly up-regulated. The activation of TNFR1, CD95 and DR4/DR5 by TNF- $\alpha$, FasL and TRAIL can trigger the activation of caspase-10, -8, -7, and -3 involved in cell death. The activated caspase- 3 can cleave its substrates such as CIDE-B to trigger chromosomal DNA fragmentation. However, the expressions of caspase-12, $-9, \mathrm{Bcl}-2$, and APAF1 were unchanged in EV71-infected cells. Previous studies reported that the death receptor pathway for apoptosis was the major pathway during the EV71 infection of RD cells [22,25]. In this study, differential changes of apoptotic gene expressions may be attributed to different conditions such as MOI, infection duration and EV71 strains.

CD40L is described originally in T lymphocytes. However, its expression has been observed in a wide variety of cells including platelets, mast cells, macrophages, basophils, NK cells, B lymphocytes as well as nonhaematopoietic cells [26]. As a member of the TNF- $\alpha$ receptor family, CD40 relies on interaction with TRAF proteins to mediate an intracellular signal in response to CD40L binding $[27,28]$. The downstream protein of TRAF2/3 can activate consecutive initiation of MEK4 and MEK7, resulting in the activation of stress-activated protein kinases JNK1/2 [29]. Subsequently, transcription factor activator of proteins (c-Fos and c-Jun) and NF- $\mathrm{kB}$ were activated through a kinase pathway involving in map kinases, NIK (NF- $\mathrm{kB}$ inducing kinase) and I-kB kinase, thus co-stimulating the proliferation of activated T-cells accompanied by the production of IFN- $\gamma$, TNF- $\alpha$, and IL-2 [28]. Interestingly, the expressions of CD40L, MEK4 and MEK7 were induced by 5.44, 2.54, and 3.05fold in RD cells at $20 \mathrm{~h}$ postinfection, whereas JNK1/2 was highly phosphorylated. Therefore, we postulated that CD40L/CD40 signaling pathway was also activated in EV71-infected RD cells.

The serine/threonine kinase AKT, also known as protein kinase $B(\mathrm{PKB})$, has become a major focus because of its critical regulatory role in cellular processes including cancer progression [30]. AKT cascades are activated by receptor tyrosine kinases, integrins, B- and T-cell receptors, cytokine receptors, G-protein coupled receptors and other stimuli for inducing the accumulation of phosphatidylinositol 3,4,5-triphosphates by phosphoinositide 3-kinase 
Table 1 Differential apoptotic gene expressions of RD cells in response to EV71 infection at 8 and $20 \mathrm{~h}$ postinfection Symbols Description of genes EV71/control (Fold changes)

$8 \mathrm{~h}$ $20 \mathrm{~h}$

\begin{tabular}{|c|c|c|c|}
\hline ACIN1 & Apoptotic chromatin condensation inducer 1 (ACINUS; ACN; fSAP152) & -3.17 & 1.33 \\
\hline AIFM1 & Apoptosis-inducing factor 1 (AIF; COXPD6; PDCD8) & 1.03 & -1.33 \\
\hline AlFM2 & Apoptosis-inducing factor, mitochondrion-associated, 2 (AMID; PRG3; RP11-367H5.2) & -3.83 & -1.25 \\
\hline$\overline{\text { Akt1 }}$ & V-akt murine thymoma viral oncogene homolog 1 (AKT1; PKB; PKB-ALPHA; PRKBA; RAC; RAC-ALPHA) & -9.89 & -1.13 \\
\hline Akt2 & V-akt murine thymoma viral oncogene homolog 2 (AKT2, PKBB; PKBBETA; PRKBB; RAC-BETA) & -3.36 & 2.66 \\
\hline Akt3 & V-akt murine thymoma viral oncogene homolog 3(AKT3) & -1.06 & 1.58 \\
\hline APAF1 & Apoptotic peptidase activating factor 1 (APAF-1; CED4) & -4.10 & 1.09 \\
\hline$\overline{\mathrm{API}}$ & Apoptosis inhibitor 5 (AAC-11; AAC11) & -5.41 & 1.06 \\
\hline $\mathrm{BCl}-2$ & B-cell lymphoma 2 (BCL-2) & -1.07 & -1.43 \\
\hline BIRC2 & Baculoviral IAP repeat-containing 2 & 1.56 & 1.23 \\
\hline BIRC3 & Baculoviral IAP repeat-containing 3 (AIP1; API2; CIAP2; HAIP1; HIAP1; MALT2; MIHC; RNF49; c-IAP2) & -1.84 & 3.19 \\
\hline Caspase-3 & Apoptosis-related cysteine peptidase 3(Casp3) & 1.91 & 2.38 \\
\hline Caspase-4 & Apoptosis-related cysteine peptidase 4(Casp4) & -1.31 & 1.15 \\
\hline Caspase-7 & Apoptosis-related cysteine peptidase 7(Casp7) & -2.15 & 2.03 \\
\hline Caspase-8 & Apoptosis-related cysteine peptidase 8(Casp8) & 1.87 & 2.17 \\
\hline Caspase-9 & Apoptosis-related cysteine peptidase 9(Casp9) & -4.98 & -1.02 \\
\hline Caspase-10 & Apoptosis-related cysteine peptidase 10(Casp10) & 1.25 & 2.16 \\
\hline Caspase-12 & Apoptosis-related cysteine peptidase 12 (Casp12) & 1.24 & 1.10 \\
\hline CD5 & CD5 molecule & -2.41 & 4.77 \\
\hline CD70 & CD70 molecule & 1.55 & 4.04 \\
\hline CD40L & CD40 ligand & -2.51 & 5.44 \\
\hline CD24 & CD24 molecule & 1.53 & 2.98 \\
\hline $\mathrm{CD} 27$ & CD27 molecule & -2.37 & 1.71 \\
\hline c-Fos & c-fos proto-oncogene & 2.34 & 3.23 \\
\hline c-Jun & c-Jun proto-oncogene & 1.69 & 5.52 \\
\hline CIDEA & Cell death-inducing DFFA-like effector a & -1.32 & -1.58 \\
\hline CIDEB & Cell death-inducing DFFA-like effector $b$ & -2.67 & 2.98 \\
\hline$\overline{D A P K 1}$ & Death-associated protein kinase 1 & -2.80 & 1.24 \\
\hline DAPK2 & Death-associated protein kinase 2 & -1.81 & 1.32 \\
\hline DAPK3 & Death-associated protein kinase 3 (ZIP; ZIPK) & -10.17 & 2.06 \\
\hline DFFA & DNA fragmentation factor subunit alpha (DFF-45; DFF1; ICAD) & -2.09 & -1.14 \\
\hline E2F1 & Transcription factor E2F1 (RBAP1; RBBP3; RBP3) & -3.99 & -1.17 \\
\hline E2F2 & Transcription factor E2F2 & -1.64 & 1.55 \\
\hline$\overline{E G F R}$ & Epidermal growth factor receptor & -4.78 & 1.38 \\
\hline ENDOG & Endonuclease G & -11.37 & 1.06 \\
\hline ERBB3 & Receptor tyrosine-protein kinase erbB-3 (ErbB-3; HER3; MDA-BF-1; c-erbB-3; p180-ErbB3; p45-sErbB3; p85-sErbB3) & -2.29 & 1.54 \\
\hline FADD & Fas-associated protein with death domain (MORT1) & -1.48 & -1.42 \\
\hline FasL & Fas ligand (FAS L, CD95L; CD178; TNFSF6) & -1.14 & 7.53 \\
\hline Fas & Fas receptor (ALPS1A; APO-1; APT1; CD95; FAS1; FASTM; TNFRSF6) & -1.23 & 3.26 \\
\hline IFN-a2 & Interferon alpha-2 & 1.13 & 1.54 \\
\hline IFN- $\beta 1$ & Interferon beta & 5.22 & 1.47 \\
\hline IGF1 & Insulin-like growth factor 1 (IGF-l; IGF1A; IGFI) & -1.14 & -1.15 \\
\hline
\end{tabular}


Table 1 Differential apoptotic gene expressions of RD cells in response to EV71 infection at 8 and 20 h postinfection (Continued)

\begin{tabular}{|c|c|c|c|}
\hline IGF1 R & Insulin-like Growth Factor 1 (IGF-1), Receptor (CD221; IGFIR; IGFR; JTK13) & -3.50 & 1.27 \\
\hline IKBKB & inhibitor of nuclear factor kappa-B kinase subunit beta (IKK-beta; IKK2; IKKB; NF-KBIKB) & -3.52 & 1.33 \\
\hline IKBKG & inhibitor of nuclear factor kappa-B kinase subunit gamma (AMCBX1; FIP3; IKK-gamma; IP1; IP2; IPD2; NEMO) & -5.76 & 1.40 \\
\hline IL-10 & Interleukin 10 & 1.10 & 12.15 \\
\hline IL-1a & Interleukin-1 alpha & -2.60 & 1.64 \\
\hline IL-1 $\beta$ & Interleukin-1 beta & -2.20 & 1.30 \\
\hline IL-2 & Interleukin 2 & 1.24 & 12.15 \\
\hline $\mathrm{IL}-4$ & Interleukin 4 & -3.72 & 2.39 \\
\hline IL-6R & Interleukin 6 receptor (CD126) & -5.80 & 1.92 \\
\hline IL-7 & Interleukin 7 & -1.65 & 1.26 \\
\hline IRAK1 & Interleukin-1 receptor-associated kinase 1 & -3.70 & 3.39 \\
\hline JAK2 & Janus kinase 2 (JTK10; THCYT3) & 1.06 & -1.21 \\
\hline MAP3K1 & Mitogen-activated protein kinase kinase kinase 1 (MAPKKK1; MEKK; MEKK 1; MEKK1; SRXY6) & -4.55 & 1.51 \\
\hline MAP3K5 & Mitogen-activated protein kinase kinase kinase 5 (ASK1; MAPKKK5; MEKK5) & -2.39 & 1.99 \\
\hline MAP2K4 & Mitogen-activated protein kinase kinase 4 (JNKK1; MAPKK4; MEK4) & -1.06 & 2.54 \\
\hline MAP2K7 & Mitogen-activated protein kinase kinase 7(MAPKK7; MEK7) & -1.09 & 3.05 \\
\hline MAPK1 & Mitogen-activated protein kinase 1 (ERK; ERK2; ERT1; MAPK2; P42MAPK; PRKM1; PRKM2; p38; p40; p41) & -2.21 & 1.00 \\
\hline MAPK3 & Mitogen-activated protein kinase 3(ERK1; HS44KDAP; P44ERK1; P44MAPK; PRKM3; p44-ERK1; p44-MAPK) & -2.74 & 1.67 \\
\hline MAPK8 & Mitogen-activated protein kinase 8(JNK; JNK1; SAPK1) & 1.73 & 2.53 \\
\hline MAPK9 & Mitogen-activated protein kinase 9(JNK2; JNK2A; JNK2B; SAPK) & 1.02 & 2.25 \\
\hline MYD88 & Myeloid differentiation primary response gene (88) & -6.09 & 1.82 \\
\hline NF-KB1 & Nuclear factor NF-kappa-B p105 subunit(NFKB-p105; NFKB-p50; NFkappaB; p105; p50) & -4.81 & 1.18 \\
\hline NF-KB3 & Transcription factor p65 (RELA; NF-KB p65) & -1.35 & 2.63 \\
\hline NF-KBIA & Nuclear factor of kappa light polypeptide gene enhancer in B-cells inhibitor, alpha (IKBA; MAD-3; NFKBI) & 1.49 & 2.96 \\
\hline NTRK1 & Neurotrophic tyrosine kinase receptor type 1(MTC; TRK; TRK1; TRKA; Trk-A; p140-TrkA) & -2.84 & 1.33 \\
\hline PDCD1 & Programmed cell death protein 1( CD279; PD-1; hPD-I) & -1.63 & 4.48 \\
\hline PDCD4 & Programmed cell death protein 4 & -1.30 & 1.06 \\
\hline PDCD 7 & Programmed cell death protein 7 & 1.87 & 1.42 \\
\hline PI3K-a & Phosphoinositide-3-kinase, catalytic, alpha polypeptide(PIK3CA; p110-alpha; PI3K) & -1.26 & 1.04 \\
\hline $\mathrm{PI} 3 \mathrm{~K}-\mathrm{\gamma}$ & Phosphatidylinositol-4,5-bisphosphate 3-kinase catalytic subunit gamma isoform (PIK3CG ; PI3K; PI3Kgamma; PIK3) & -1.40 & 5.18 \\
\hline PIK3R2 & Phosphatidylinositol 3-kinase regulatory subunit beta(P85B; p85; p85-BETA) & -2.12 & -1.20 \\
\hline PPP3R1 & protein phosphatase 2 B regulatory subunit 1(CALNB1; CNB; CNB1) & -1.52 & 1.94 \\
\hline RIPK1 & Receptor-interacting serine/threonine-protein kinase 1(RIP; RIP1) & -2.44 & 1.24 \\
\hline STAT1 & Signal transducers and activators of transcription (CANDF7; ISGF-3; STAT91) & -6.18 & 4.04 \\
\hline STAT5A & Signal transducer and activator of transcription $5 \mathrm{~A}$ & -1.14 & -1.15 \\
\hline STAT5B & Signal transducer and activator of transcription $5 \mathrm{~B}$ & -3.17 & 1.08 \\
\hline TGFB1 & Transforming growth factor beta 1(CED; DPD1; LAP; TGFB; TGFbeta) & -2.23 & -1.15 \\
\hline TNF-a & Tumor necrosis factors & -1.97 & 2.19 \\
\hline TNFRSF10A & Tumor necrosis factor receptor superfamily member 10A (APO2; CD261; DR4; TRAILR-1; TRAILR1) & -2.82 & 2.03 \\
\hline TNFRSF10B & Tumor necrosis factor receptor superfamily member 10B (DR5, CD262, TRICK2, TRICKB, TRAILR2, TRICK2A, TRICK2B) & -2.84 & 1.02 \\
\hline P53 & Tumor protein 53(LFS1; TP53; TRP53) & -7.60 & 1.32 \\
\hline XIAP & X-linked inhibitor of apoptosis protein(API3; BIRC4; IAP-3; ILP1; MIHA; XLP2; hIAP3) & -1.94 & 2.59 \\
\hline
\end{tabular}

Negative values indicate down-regulation of genes.

(PI3K) [31]. Three AKT isoforms (AKT1, AKT2 and AKT3) can mediate many downstream events regulated by PI3K. At $8 \mathrm{~h}$ postinfection, the expression of AKT2 was significantly down-regulated by 3.36 fold, while PI3K and AKT2 were enhanced by 5.18 fold and 2.66 fold at $20 \mathrm{~h}$ postinfection, respectively. The phosphorylation of AKT2 was highly elevated. As previously reported, EV71 can activate PI3K/AKT to trigger the anti-apoptotic 
A

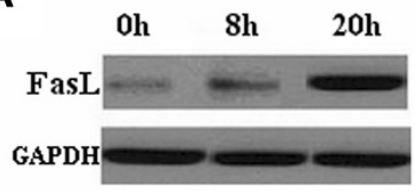

B Oh $\quad 3 \mathrm{~h} \quad 8 \mathrm{~h} \quad 20 \mathrm{~h} \quad 24 \mathrm{~h}$
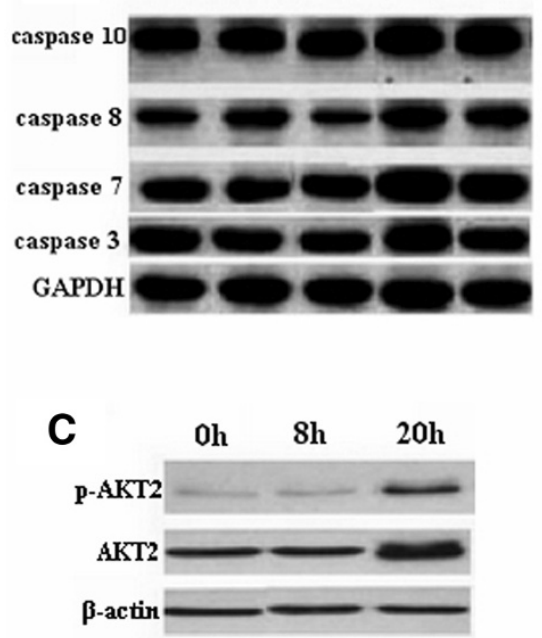

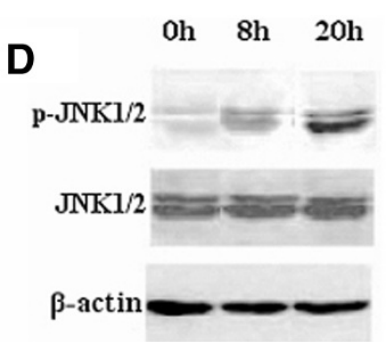

E Oh $8 \mathrm{~h} \quad 20 \mathrm{~h}$
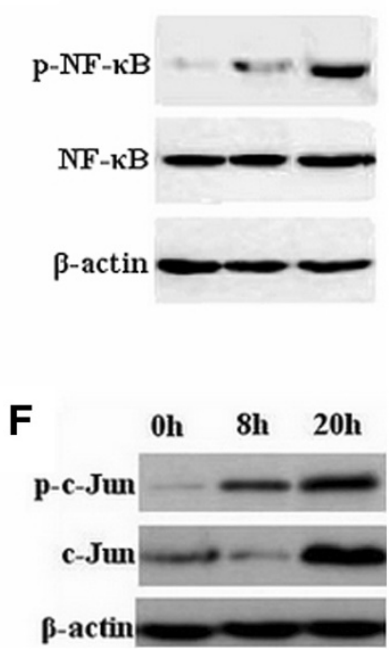

Figure 7 EV71 infection induced activation of apoptotic signal pathway proteins. Cell lysates were prepared from EV71-infected RD cells at the indicated time and resolved with 12\% SDS-PAGE. Proteins were transferred onto PVDF membranes and subjected to western blotting. (A) FasL expression in EV71- infected RD cells at 0, 8, and 20 h. (B) Western blot analysis for caspase-10, -8, -7, and -3 in EV71- infected RD cells at 0, 3, 8, 20 and $24 \mathrm{~h}$. GAPDH was probed as the loading control. The phosphorylated or total proteins of AKT2 (C), JNK1/2 (D), NF-KB (E) and c-Jun (F) were detected by western blotting at 0,8 , and $20 \mathrm{~h}$. The amounts of $\beta$-actin were also assessed to monitor the equal loadings of protein extracts.

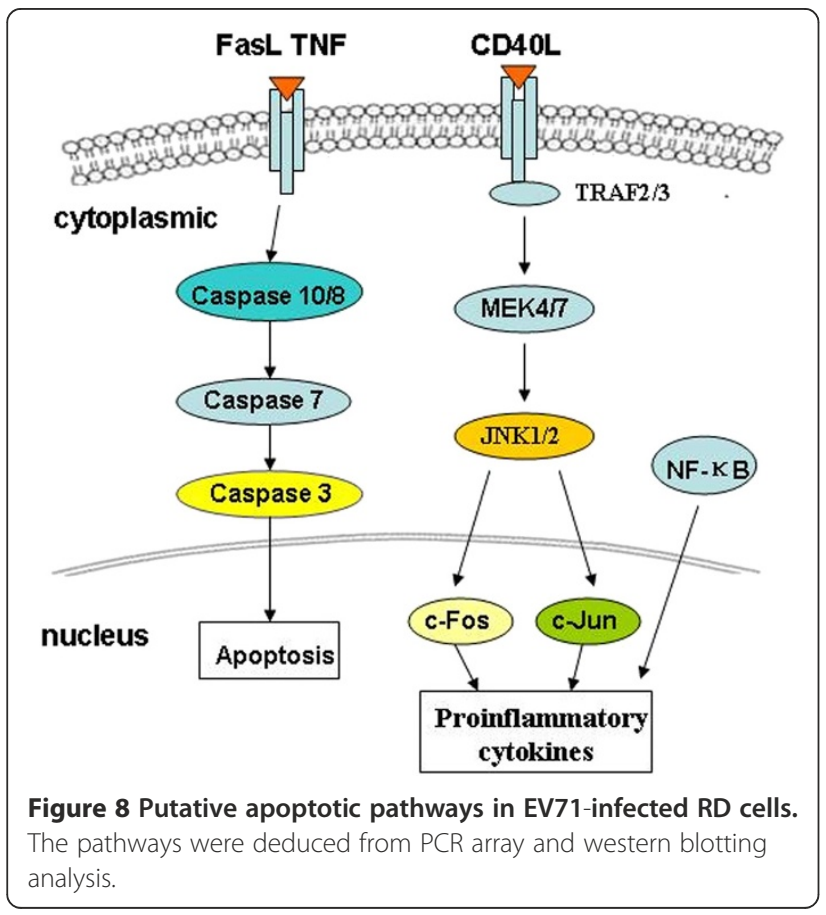

pathways at the early phase during infection [32,33]. In this study, the activation of PI3K/AKT may be associated with EV71 strain virulence and virus titer.

Transcription factor NF-kB p65 (NF-kB3) is a protein encoded RELA gene in human. Activated NF- $\mathrm{kB}$ p 65 translocates into the nucleus and binds DNA at kappaB-binding motifs, thus being involved in the production of cytokines including IL-2, IL- 6 , TNF- $\alpha$, IFN- $\beta$ and IL-1 $\beta[34,35]$. While STAT1 is a member of the signal transducers and activators of transcription family and involved in the up-regulation of the genes through type I, type II or type III interferon [36]. Both NF- $k B$ and STAT1 are rapidly activated in response to various stimuli including viral infection and cytokines, thus controlling the expressions of anti-apoptotic, pro-proliferative and immune response genes. In this study, NF- $\mathrm{kB}$ p 65 and STAT1 were upregulated by 2.63 and 4.04 fold, respectively. Meanwhile, NF-кB p65 was significantly phosphorylated at $20 \mathrm{~h}$ postinfection. However, NF-кBIA was up-regulated by 2.96 fold, which can block NF-kB to bind to DNA. IL-2, IL-4, IL-10 and TNF- $\alpha$ exhibited the 
enhancement by $12.15,2.39,12.15$ and 2.19 fold at $20 \mathrm{~h}$ after EV71 infection. Compared with EV71-uninfected controls, the expression levels of IL-4, IL-10 and TNF- $\alpha$ in EV71-infected RD cells revealed a significant increase at 20 and $32 \mathrm{~h}$ postinfection $(P<0.01$,or $P<0.001)$.

Eight human IAPs such as NAIP (BIRC1), c-IAP1 (BIRC2), c-IAP2 (BIRC3), X-linked IAP (XIAP, BIRC4), Survivin (BIRC5), Apollon (BRUCE, BIRC6), Livin/ ML-IAP (BIRC7) and IAP-like protein 2 (BIRC8) have been identified $[37,38]$. BIRC3 can participate in TNF- $\alpha$ mediated NF- $\mathrm{KB}$ activation, while XIAP can bind to the active site of effector caspases including caspase-3, caspase- 7 and caspase- 9 for preventing substrate binding and subsequent catalysis through its BIR2 domain with N-terminal linker [39]. BIRC3 and XIAP were significantly up-regulated by 3.19 fold and 2.59 fold at $20 \mathrm{~h}$ postinfection, which may be related to the apoptosis inhibition of RD cells. Additionally, the up-regulation of CD5, CD24, CD70, CD226 and PDCD1 (PD-1) that usually express on the surface of $T$ cells, $B$ cells, dendritic cells, NK cells, and tumor cells have also been observed [40-44]. Interestingly, these genes revealed a significant up-regulation in EV71-infected RD cells and may be associated with cell signal pathway and apoptosis. Therefore, further study is needed to be undertaken for these gene expressions.

\section{Conclusions}

PCR array is an effective method to analyze differential gene expressions on cellular signaling pathways. The results showed that RD cells have a general trend to inhibit cell proliferation and delay the apoptotic process during the early stage of EV71 infection. EV71 inducedapoptosis may be associated with the activation of Fas, CD40 and TNF death receptor as well as the cleavage of initiator caspases including caspase-10 and -8. However, the activation of caspase-12, -9 and APAF1 in mitochondrial apoptotic pathway and endoplasmic reticulum stress was not completed in EV71-infected RD cells, which may be associated with MOI, infection duration and EV71 strains, etc. In response to EV71 infection, both NF-KB and c-Jun are activated to translocate into the nucleus to induce the production of IL-4, IL-10 and TNF- $\alpha$. Thus, our findings will provide a theoretical evidence for reducing cell damage and intervening EV71 infection process.

\section{Competing interests}

The authors declare that they have no competing interests.

\section{Authors' contributions}

WS designed the experiments, and participated in data analysis and manuscript writing. $\mathrm{XL}, \mathrm{XH}$ and HP performed RD cell culture, flow cytometry analysis and PCR. QJ participated in coordination and partial data analysis of experiments. MS and YJ performed cell viability counts and partial data analysis. XL and JL designed ELISA assays and the detection of cytokines. All authors reviewed and approved the final manuscript.

\section{Acknowledgements}

The authors would like to thank Guanghua Luo and Jingting Jiang for their help in flow cytometry and statistical analysis.

\section{Author details}

'Department of Clinical Laboratory, The Third Affiliated Hospital of Suzhou University, Changzhou, Jiangsu 213003, China. ${ }^{2}$ Department of Orthopedics, The Third Affiliated Hospital of Suzhou University, Changzhou, Jiangsu 213003, China

Received: 12 November 2012 Accepted: 23 November 2012 Published: 28 November 2012

\section{References}

1. Yan JJ, Su IJ, Chen PF, Liu CC, Yu CK, Wang JR: Complete genome analysis of enterovirus 71 isolated from an outbreak in Taiwan and rapid identification of enterovirus 71 and coxsackievirus A16 by RT-PCR. J Med Virol 2001, 65:331-339.

2. Brown BA, Pallansch MA: Complete nucleotide sequence of enterovirus 71 is distinct from poliovirus. Virus Res 1995, 39:195-205.

3. Zhang Y, Tan XJ, Wang HY, Yan DM, Zhu SL, Wang DY, Ji F, Wang XJ, Gao YJ, Chen L, An HQ, Li DX, Wang SW, Xu AQ, Wang ZJ, Xu WB: An outbreak of hand, foot, and mouth disease associated with subgenotype C4 of human enterovirus 71 in Shandong, China. J Clin Virol 2009, 44:262-267.

4. Chang LY, Lin TY, Hsu KH, Huang YC, Lin KL, Hsueh C, Shih SR, Ning HC, Hwang MS, Wang HS, Lee CY: Clinical features and risk factors of pulmonary oedema after enterovirus-71-related hand, foot, and mouth disease. Lancet 1999, 354:1682-1686.

5. Lum LC, Wong KT, Lam SK, Chua KB, Goh AY, Lim WL, Ong BB, Paul G, AbuBakar S, Lambert M: Fatal enterovirus 71 encephalomyelitis. J Pediatr 1998, 133:795-798.

6. Schmidt NJ, Lennette EH, Ho HH: An apparently new enterovirus isolated from patients with disease of the central nervous system. J Infect Dis 1974, 129:304-309.

7. Wang SM, Liu CC, Tseng HW, Wang JR, Huang CC, Chen YJ, Yang YJ, Lin SJ, Yeh TF: Clinical spectrum of enterovirus 71 infection in children in southern Taiwan, with an emphasis on neurological complications. Clin Infect Dis 1999, 29:184-190.

8. McMinn P, Lindsay K, Perera D, Chan HM, Chan KP, Cardosa MJ: Phylogenetic analysis of enterovirus 71 strains isolated during linked epidemics in Malaysia, Singapore, and Western Australia. J Virol 2001, 75:7732-7738.

9. Ma E, Chan KC, Cheng P, Wong C, Chuang SK: The enterovirus 71 epidemic in 2008-public health implications for Hong Kong. Int J Infect Dis 2010, 14:e775-e780.

10. Li L, He Y, Yang H, Zhu J, Xu X, Dong J, Zhu Y, Jin Q: Genetic characteristics of human enterovirus 71 and coxsackievirus A16 circulating from 1999 to 2004 in Shenzhen, People's Republic of China. J Clin Microbiol 2005, 43:3835-3839.

11. Chua KB, Kasri AR: Hand foot and mouth disease due to enterovirus 71 in Malaysia. Virol Sin 2011, 26:221-228.

12. Shore GC, Papa FR, Oakes SA: Signaling cell death from the endoplasmic reticulum stress response. Curr Opin Cell Biol 2011, 23:143-149.

13. Krampe B, Al-Rubeai M: Cell death in mammalian cell culture: molecular mechanisms and cell line engineering strategies. Cytotechnology 2010, 62:175-188.

14. Leong WF, Chow VT: Transcriptomic and proteomic analyses of rhabdomyosarcoma cells reveal differential cellular gene expression in response to enterovirus 71 infection. Cell Microbiol 2006, 8:565-580.

15. Clem R, Miller $\mathrm{L}$ : Apoptosis reduces both the in vitro replication and the in vivo infectivity of a baculovirus. J Virol 1993, 67:3730-3738.

16. Sun E, Shi Y: Apoptosis: the quiet death silences the immune system. Pharmacol Ther 2001, 92:135-145.

17. Liang CC, Sun MJ, Lei HY, Chen SH, Yu CK, Liu CC, Wang JR, Yeh TM: Human endothelial cell activation and apoptosis induced by enterovirus 71 infection. J Med Virol 2004, 74:597-603.

18. Chen LC, Shyu HW, Chen SH, Lei HY, Yu CK, Yeh TM: Enterovirus 71 infection induces Fas ligand expression and apoptosis of Jurkat cells. J Med Virol 2006, 78:780-786.

19. Weng KF, Chen LL, Huang PN, Shih SR: Neural pathogenesis of enterovirus 71 infection. Microbes Infect 2010, 12:505-510. 
20. Hung HC, Chen TC, Fang MY, Yen KJ, Shih SR, Hsu JT, Tseng CP: Inhibition of enterovirus 71 replication and the viral 3D polymerase by aurintricarboxylic acid. J Antimicrob Chemother 2010, 65:676-683.

21. Szegezdi E, Macdonald DC, Ni-Chonghaile T, Gupta S, Samali A: Bcl-2 family on guard at the ER. Am J Physiol Cell Physiol 2009, 296:C941-C953.

22. Chang SC, Lin JY, Lo LY, Li ML, Shih SR: Diverse apoptotic pathways in enterovirus 71-infected cells. J Neurovirol 2004, 10:338-349.

23. Abendroth A, Kinchington PR, Slobedman B: Varicella zoster virus immune evasion strategies. Curr Top Microbiol Immunol 2010, 342:155-171.

24. Lin YW, Wang SW, Tung YY, Chen SH: Enterovirus 71 infection of human dendritic cells. Exp Biol Med (Maywood) 2009, 234:1166-1173.

25. Farley SM, Purdy DE, Ryabinina OP, Schneider P, Magun BE, lordanov MS: Fas ligand-induced proinflammatory transcriptional responses in reconstructed human epidermis. Recruitment of the epidermal growth factor receptor and activation of MAP kinases. J Biol Chem 2008, 283:919-928.

26. Lee W, Qin X, Wang Y, Zheng G, Ince J, Tan TK, Kairaitis LK, Alexander SI, Harris DC: The CD40-CD154 co-stimulation pathway mediates innate immune injury in adriamycin nephrosis. Nephrol Dial Transplant 2010, 25:717-730.

27. Jundi M, Nadiri A, Al-Zoobi L, Hassan GS, Mourad W: CD40-mediated cell death requires TRAF6 recruitment. Immunobiology 2012, 217:375-383.

28. Elgueta R, Benson MJ, de Vries VC, Wasiuk A, Guo Y, Noelle RJ: Molecular mechanism and function of CD40/CD40L engagement in the immune system. Immunol Rev 2009, 229:152-172.

29. Rau SJ, Hildt E, Himmelsbach K, Thimme R, Wakita T, Blum HE, Fischer R: CD40 inhibits replication of hepatitis $C$ virus in primary human hepatocytes by JNK activation independent from the interferon pathway. Hepatology 2012, doi:10.1002/hep.25966.

30. Dillon RL, Muller WJ: Distinct biological roles for the akt family in mammary tumor progression. Cancer Res 2010, 70:4260-4264.

31. Tong KM, Shieh DC, Chen CP, Tzeng CY, Wang SP, Huang KC, Chiu YC, Fong $Y C$, Tang $\mathrm{CH}$ : Leptin induces IL-8 expression via leptin receptor, IRS-1, PI3K, Akt cascade and promotion of NF-kappaB/p300 binding in human synovial fibroblasts. Cell Signal 2008, 20:1478-1488.

32. Wong WR, Chen YY, Yang SM, Chen YL, Horng JT: Phosphorylation of $\mathrm{PI} 3 \mathrm{~K} / \mathrm{Akt}$ and MAPK/ERK in an early entry step of enterovirus 71. Life SCi 2005, 78:82-90.

33. Autret A, Martin-Latil S, Brisac C, Mousson L, Colbere-Garapin F, Blondel B: Early phosphatidylinositol 3-kinase/Akt pathway activation limits poliovirus-induced JNK-mediated cell death. J Virol 2008, 82:3796-3802.

34. Piva R, Belardo G, Santoro MG: NF-kappaB: a stress-regulated switch for cell survival. Antioxid Redox Signal 2006, 8:478-486.

35. Mauro C, Zazzeroni F, Papa S, Bubici C, Franzoso G: The NF-kappaB transcription factor pathway as a therapeutic target in cancer: methods for detection of NF-kappaB activity. Methods Mol Biol 2009, 512:169-207.

36. Sow FB, Alvarez GR, Gross RP, Satoskar AR, Schlesinger LS, Zwilling BS, Lafuse WP: Role of STAT1, NF-kappaB, and C/EBPbeta in the macrophage transcriptional regulation of hepcidin by mycobacterial infection and IFN-gamma. J Leukoc Biol 2009, 86:1247-1258.

37. Gill C, Dowling C, O'Neill AJ, Watson RW: Effects of CIAP-1, CIAP-2 and XIAP triple knockdown on prostate cancer cell susceptibility to apoptosis, cell survival and proliferation. Mol Cancer 2009, 8:39.

38. Augello C, Caruso L, Maggioni M, Donadon M, Montorsi M, Santambrogio R, Torzilli G, Vaira V, Pellegrini C, Roncalli M, Coggi G, Bosari S: Inhibitors of apoptosis proteins (IAPs) expression and their prognostic significance in hepatocellular carcinoma. BMC Cancer 2009, 9:125.

39. Jin HS, Lee DH, Kim DH, Chung JH, Lee SJ, Lee TH: CIAP1, CIAP2, and XIAP act cooperatively via nonredundant pathways to regulate genotoxic stress-induced nuclear factor-kappaB activation. Cancer Res 2009, 69:1782-1791.

40. Dalloul A: CD5: a safeguard against autoimmunity and a shield for cancer cells. Autoimmun Rev 2009, 8:349-353.

41. Minton K: T cell memory: Exhausted T cells miss out on methylation. Nat Rev Immunol 2011, 11:718-719.

42. Overdevest JB, Thomas S, Kristiansen G, Hansel DE, Smith SC, Theodorescu D: CD24 offers a therapeutic target for control of bladder cancer metastasis based on a requirement for lung colonization. Cancer Res 2011, 71:3802-3811.

43. Zwart W, Peperzak V, de Vries E, Keller AM, van der Horst G, Veraar EAM, Geumann U, Janssen H, Janssen L, Naik SH: The invariant chain transports
TNF family member CD70 to MHC class II compartments in dendritic cells. J Cell Sci 2010, 123:3817-3827.

44. Tahara-Hanaoka S, Shibuya K, Onoda Y, Zhang H, Yamazaki S, Miyamoto A, Honda S, Lanier LL, Shibuya A: Functional characterization of DNAM-1 (CD226) interaction with its ligands PVR (CD155) and nectin-2 (PRR-2/CD112). Int Immunol 2004, 16:533-538.

doi:10.1186/1471-2334-12-327

Cite this article as: Shi et al:: Differential apoptosis gene expressions of rhabdomyosarcoma cells in response to enterovirus 71 infection. BMC Infectious Diseases 2012 12:327.

\section{Submit your next manuscript to BioMed Central and take full advantage of:}

- Convenient online submission

- Thorough peer review

- No space constraints or color figure charges

- Immediate publication on acceptance

- Inclusion in PubMed, CAS, Scopus and Google Scholar

- Research which is freely available for redistribution

Submit your manuscript at www.biomedcentral.com/submit
C) BioMed Central 